\title{
North America, Central America and Caribbean (2019)
}

\author{
Kirsten Nakjavani Bookmiller*
}

National disaster risk profiles across the Americas range widely. On the one hand, countries such as Costa Rica, Haiti, and Nicaragua rank consistently among the highest at risk globally. Conversely, others including Canada and Grenada are among the lowest. ${ }^{1}$ Still, an array of crises beset countries across the region in 2019, regardless of risk level. The most catastrophic of the year was that of Hurricane Dorian, which struck the Bahamas on September 1, with Category 5 winds. It was the most powerful to hit the country in its recorded history and one of the strongest on record for the Atlantic. A series of earthquakes in late December surprised several countries of the Eastern Caribbean, in some instances experiencing a level of impact not felt since 1918. Climate change also exacerbated more commonly occurring events across the Western Hemisphere, including tropical storms, floods, tornadoes, and wildfires.

This entry will survey sector-related legal and institutional developments occurring in 2019 on the regional, subregional and national levels for North America, Central America, and the Caribbean. Ever mindful that in the past decade 152 million people were impacted by over 1.200 disasters in Latin America and the Caribbean - making the region the second most disaster prone globally ${ }^{2}$ - in-region intergovernmental actors continued to partner with member states and other sector stakeholders in advancing legal preparedness as a path toward risk reduction. In the meantime, North America continued to cultivate a dialogue space around significant legal, policy and operational challenges to mutual assistance, given increasingly intensifying hazard driven crises in all three countries.

* PhD in Foreign Affairs (University of Virginia); Professor, Department of Government and Center for Disaster Research and Education, Millersville University (USA); Policy Advisor, Humanitarian Services, American Red Cross.

1 Bündnis Entwicklung Hilft and Ruhr University Bochum-Institute for International Law of Peace and Armed Conflict, 'World Risk Report 2019' <https://reliefweb.int/sites/reliefweb .int/files/resources/WorldRiskReport-2019_Online_english.pdf>, last accessed (as any subsequent URL) on 1 June 2020 .

2 осна, 'Natural Disasters in Latin America and The Caribbean, 2000-2019' (March 2020) $<$ https://reliefweb.int/sites/reliefweb.int/files/resources/20191203-ocha-desastres_natura les.pdf $>$. 
The Sendai Framework's Priority 4, Paragraph 34 (a) encourages the development and strengthening of 'coordinated regional approaches and operational mechanisms to prepare for and ensure rapid and effective disaster response in situations that exceed national coping capacities (...)'. Against the backdrop of several record breaking disasters in all three countries in both 2017 and 2018, including hurricanes, wildfires and flooding, Canada, Mexico and the United States maintained a dialogue in 2019 on legal and regulatory barriers to cross-border mutual assistance through the North American Humanitarian Response Initiative (NAH RI). A successor effort to the historic 2017-2018 North American Humanitarian Response Summit (NAHRS), ${ }^{3}$ NAH RI's main purpose was to foster a humanitarian-focused diplomatic process for North America aimed at strengthening cross-border response to all hazards. It did so through three Thematic Working Groups (TWGs): 1) Specialized Teams and Personnel, 2) Supplies and Equipment, and 3) Accountability to Underserved Populations. Conducted through the facilitation of the American Red Cross, the TwGs included federal, state and provincial level government and National Society representatives from all three countries, the International Federation of Red Cross and Red Crescent Societies, disaster response practitioners, and policy experts.

The Initiative convened three in-person workshops. They were held in February 2019 in Canada and the United States (which focused explicitly on potential contributions of International Disaster Law) and in March 2019 in Mexico. The project also generated an updated legal mapping of germane national, bilateral, and trilateral legal and policy instruments related to North American cross-border aid (both governmental and Red Cross). ${ }^{4}$

While NAHRI concluded in March 2019 with the end of donor funding, the three National Societies pledged to continue leveraging their auxiliary and operational roles to improve the effectiveness of cross-border response to disasters in North America' at the 33rd International Conference of the Red Cross and Red Crescent in December 2019 in Geneva. ${ }^{5}$ The pledge incorporated an Action Plan

3 For further background on the NAHRS initiative, please refer to Kirsten Nakjavani Bookmiller, 'North America, Central America and Caribbean (2018)', (2019) 1 Yearbook of International Disaster Law, $35^{6-357 .}$

4 Kirsten Nakjavani Bookmiller, 'Multinational Legal and Policy Preparedness Scan 2019 Update', Commissioned by American Red Cross, March 2019.

5 'Improving the effectiveness of cross-border response to disasters and other emergencies in North America', Pledge, 33rd International Conference of the Red Cross and Red Crescent (9-12 December 2019) <https://rcrcconference.org/pledge/improving-the-effec tiveness-of-cross-border-response-to-disasters-and-other-emergencies-in-north-america/>. 
to be implemented between 2019-2023, including continued engagement with public authorities on the matter and dissemination of best practices in the sector.

On the national level, Canada's Federal government along with its Provinces, Territories and Indigenous communities issued a new Emergency Management Strategy for Canada: Toward a Resilient 2030. ${ }^{6}$ Drafted over a two year, multistakeholder engagement process, the Strategy 'helps fulfill the Government of Canada's commitment under the Sendai Framework for a pan-Canadian DRR Strategy and aligns with the Sendai Framework's 2030 timeline. ${ }^{7}$ On the provincial level, British Columbia - the first province to adopt Sendai ${ }^{8}$ in October 2018 after catastrophic flooding and wildfires - launched a modernization process of its two decade old Emergency Program Act to fully align with Sendai's provisions, a process that is on-going. ${ }^{9}$

\section{$2 \quad$ Central America}

In one of the most disaster vulnerable areas in the world, the Central American Integration System (SICA) ${ }^{10}$ sustained its advocacy of the importance of regional and international disaster law instruments among member states and other invested parties. SICA advances this agenda primarily through its Coordination Center for the Prevention of Disasters in Central America and the Dominican Republic (CEPREDENAC). ${ }^{11}$ It was in fact CEPREDENAC that represented the region at the Sixth Session of the Global Platform for Disaster Risk Reduction held in Geneva in May 2019 (GP2O19).12

6 Available at <https://www.publicsafety.gc.ca/cnt/rsrcs/pblctns/mrgncy-mngmnt-strtgy/ mrgncy-mngmnt-strtgy-en.pdf $>$.

$7 \quad$ Public Safety Canada, 'Emergency Management Strategy for Canada: Toward a Resilient 203o' (25 January 2019) <https://www.publicsafety.gc.ca/cnt/rsrcs/pblctns/mrgncy-mng mnt-strtgy/index-en.aspx $>$.

8 Although it should be noted that the Province of Québec's 2014-2024 Emergency Management Policy and National Action Plan were designed to align with the Hyogo Framework, Sendai's predecessor.

9 Emergency Management British Columbia, 'Government's Action Plan: Responding to Wildfire and Flood Risks' (31 October 2019 Update) <https://www2.gov.bc.ca/assets/ gov/public-safety-and-emergency-services/emergency-preparedness-response-recovery/ embc/action_plan.pdf>.

10 Bündnis Entwicklung Hilft and Ruhr University Bochum-Institute for International Law of Peace and Armed Conflict (n 1 ).

11 For in-depth background to both SICA and CEPREDENAC efforts in this area, refer to Nakjavani Bookmiller (n 3) 357-358.

12 'Declaración Oficial del CEPREDENAC Sexta Sesión de la Plataforma Mundial para la Reducción del Riesgo de Desastres (GP2019) Ginebra, Suiza, 13 al 17 de mayo del año 
During the year, SICA's efforts were largely driven by a DRR agenda, especially deepening member states' engagement with the 2017 Central American Policy on Comprehensive Disaster Risk Management, 2017-2030 (PCGIR). ${ }^{13}$ The organization's principal guiding instrument in the area of disaster risk management, the PCGIR was updated in 2017 to fully align with Sendai, the 2030 Agenda for Sustainable Development and the Paris Agreement on Climate Change.

CEPREDENAC organized several bilateral and multilateral meetings with sICA member governments, the World Bank, civil society and academia to build awareness of the PCGIR and its important role in fulfilling the Sendai Framework. ${ }^{14}$ In light of the significant food insecurity along the region's "Dry Corridor" due to persistent drought conditions, it is not surprising that SICA and CEPREDENAC heavily promoted the importance of both instruments as they intersect with agriculture. In addition to a meeting on the topic with the Central American Agricultural Council in April 2019, ${ }^{15}$ SICA organized a September 2019 workshop in Guatemala to train member governments on natural disaster-focused damage and loss measurement systems for the region's agricultural sector. Based on the Food and Agriculture Organization methodology, the process helps fulfill the PCGIR while allowing SICA to assess headway made related to Sendai's C2 Direct Agricultural Loss Indicator. ${ }^{16}$

Additionally, on the DRR front, SICA members met at the end of the year in Panama to further development of the organization's Regional Plan for Disaster Risk Reduction, 2019-2O23 (PRRD). A successor to the inaugural 2014-2019

2019' <https://www.unisdr.org/conference/2019/globalplatform/about\#: :text=The\%2O Global\%2oPlatform\%2ofor\%2oDisaster\%2oRisk\%2oReduction\%2ois\%2oa\%2o biennial,trends\%2oin\%2oreducing\%2odisaster\%2orisk.>.

13 Available at $<$ https://eird.org/americas/docs/pcgir-version-en-ingles.pdf> .

14 'Secretaría Ejecutiva del CEPREDENAC' (May 2019) <http://www.cepredenac .org/application/files/8415/6382/8072/Resumen_Ejecutivo_Secretaria_Ejecutiva_del _CEPREDENAC_05-2019_Mayo.pdf> and 'Hacia una Centroamérica más resiliente' (7 February 2019), <https://reliefweb.int/report/guatemala/hacia-una-centroam-rica -m-s-resiliente>.

15 Cepredenac, 'CePREDenAC y CAC Coordinan Acciones Para la Reducción de Riesgo de Desastres En la Región' (9 April 2019) <https://www.cepredenac.org/noticias/ cepredenac-y-cac-coordinan-acciones-para-la-reduccion-de-riesgo-de-desastres-en-la -region> accessed 1 June 2020.

16 CePredenac, 'Países del SICA se reúnen en Antigua Guatemala para fortalecer sistemas de medición de daños y pérdidas para mejorar la planificación, las inversiones, los programas agrícolas y la respuesta post-desastre' (16 September 2019) <https:// www.cepredenac.org/noticias/paises-del-sica-se-reunen-en-antigua-guatemala-para -fortalecer-sistemas-de-medicion-de-danos-y-perdidas-para-mejorar-la-planific >. 
strategy, the Panama meeting focused upon developing regional indicators to better harmonize the Plan with the PCGIR and Sendai. ${ }^{17}$

Cross-border aid protocols within Central America were a focus of cooperation in 2019 as well. The region's customs and trade authorities met in Guatemala in July to update the Central American Uniform Customs Code (CAUCA) and its Regulations (RECAUCA), in existence since 2008. While a general customs agreement, CAUCA/RECAUCA includes significant provisions covering customs processes on entering aid during emergencies. ${ }^{18}$ The first ever Regional Humanitarian Assistance Simulation, focused upon collapsed structure rescue and involving SICA member states' national urban search and rescue teams, ${ }^{19}$ was conducted in November in Nicaragua. The exercise was designed to test the 2014 Regional Mechanism for Mutual Assistance in Disasters (MecReg-SICA). The MecReg is another instrument designed to carry out the PCGIR.

On the national level, Guatemala introduced in January 2019 a new bill aimed at reforming its national disaster management framework with the aim to have it better sync with Sendai. The proposed legislation made significant progress through its Congress by year's end. Guatemala also adopted a roadmap to enhance institutional capacities for volcanic risk reduction and resilience. ${ }^{20}$ At the Sixth Session of the Global Platform for Disaster Risk Reduction, Costa Rica signaled that it was also considering further reforming its disaster management legislation and National Risk Management Plan after assessing its national commitments against the Sendai Framework Monitor indicators. ${ }^{21}$

17 UNDRR, 'Regional Consultation workshop to define the regional indicators of the Disaster Risk Reduction Plan in Central America 2019-2023' (18 December 2019) <https://www .undrr.org/event/regional-consultation-workshop-define-regional-indicators-disaster -risk-reduction-plan>.

18 SIECA, 'Se lleva a cabo la XIV Reunión para apoyar la actualización del Código Aduanero Uniforme Centroamericano y su Reglamento' (16 July 2019) < https://www.sieca.int/index .php/news/se-lleva-a-cabo-la-xiv-reunion-para-apoyar-la-actualizacion-del-codigo -aduanero-uniforme-centroamericano-y-su-reglamento/>.

19 SICA, 'Primer Simulacro Regional de Asistencia Humanitaria' (2020) <https://www.sica .int/Iniciativas/mecreg>.

20 World Bank, 'Strengthening Guatemala's Capacities to Manage Risk and Cope with the Impact of Catastrophic Events' (27 May 2019) <https://www.worldbank.org/en/news/ press-release/2019/05/27/guatemalas-capacities-to-manage-risk> and Government of the Republic of Guatemala, 'Declaración Oficial, Guatemala', Sixth Session of the Global Platform for Disaster Risk Reduction, Geneva, Switzerland (May 2019) <https://www.pre ventionweb.net/files/globalplatform/Informe\%2ode\%2oPais\%2oPGRRD\%202019.pdf>.

21 'Declaración de Costa Rica Ante la VI Sesión de la Plataforma Mundial para la Reducción del Riesgo de Desastres', Sixth Session of the Global Platform for Disaster Risk Reduction, 
The Caribbean hosts an array of intergovernmental bodies focusing upon natural disaster threats, given the region's acute vulnerability. It is exceptionally exposed to both hydro-meteorological and geophysical hazards. Moreover, $70 \%$ of its population is situated along low-lying coastal areas, along with much of its economic life and infrastructure. ${ }^{22}$

The most prominent actor in this domain is the Caribbean Community (CARICOM) and its Caribbean Disaster Emergency Management Agency (CDEMA). The overarching ethic of Comprehensive Disaster Management (CDM) informs all of CDEMA's efforts and is operationalized through a rich array of policy, legal and operational tools. ${ }^{23}$ The most central in this regard is the Regional Comprehensive Disaster Management Strategy and Programming Framework, 2014-2024 (CDM Strategy), which CDEMA considers instrumental in delivering on the region's commitment to Sendai. At the 9th meeting of CDEMA's Council in Turks \& Caicos in June and during its yearly CDM conference in Sint Maarten in December, the organization reviewed progress to date made on the CDM Strategy by the members states. ${ }^{24}$ It also represented the region at GP2O19 in May. ${ }^{25}$

One of the agency's signature initiatives relates to multi-hazard early warning systems (MHEWS). In February 2019, Saint Lucia hosted a CDEMA, UNDP and IFRC co-organized high level event on MHEWs that included the national disaster management agencies and the national Red Cross Societies of Antigua and Barbuda, Cuba, Commonwealth of Dominica, Dominican Republic, Saint Lucia and Saint Vincent and the Grenadines. The meeting assessed advancements to date on a European Commission Humanitarian Aid Office funded effort for the above six countries in relation to MHEws innovation through knowledge and tool transfer. It also sought to measure 'progress towards

Geneva, Switzerland (May 2019) <https://www.preventionweb.net/english/policies/v .php?id=68452\&cid $=41>$.

22 See осна (n 2).

23 For a more in-depth treatment of these and other documents, see Nakjavani Bookmiller (n 3) and CDEMA, 'Guidance Tools' page, <https:/www.cdema.org/virtual-library/ cdema-cu-partners-products-documents/guidance-tools $>$.

24 CDEMA, 'Council Meeting 2019' <https://www.cdema.org/council-meeting-2019>; '11th CDM Conference December 2nd-6th, 2019, Sint Maarten' <https://www.cdema.org/ $\operatorname{cdmi1} />$.

25 'Statement of the Caribbean Disaster Emergency Management Agency for the Sixth Session of the Global Platform for Disaster Risk Reduction (Gp2019) Geneva, Switzerland, 13-17 May 2019' <https://www.unisdr.org/files/globalplatform/CDEMA\%2oGP\%2O Organisational\%2oStatement\%2O2O191RJ2.pdf>. 
achieving the outcomes of the regional and global frameworks for Disaster Risk Reduction'. ${ }^{26}$ At the same meeting, Cuba, the Dominican Republic and Saint Lucia, signed historic commitment statements to further deepen efforts related to M HEWs. ${ }^{27}$ A November 2019 regional meeting was also held in Saint Lucia to approve a new National Model Multi-Hazard Early Warning Systems (MHEws) Policy and Adaptation Guide and hold consultations on a draft regional MHEws Strategy. The following month a Regional Early Warning Systems Consortium (REWSC) was formally established after a year of development meetings. All three initiatives are designed to improve regional MHEWs governance mechanisms and guidance tools, two previously identified weaknesses in the sector. ${ }^{28}$

In other sectorial developments, the Second Ministerial Forum on School Safety in the Caribbean took place in Saint Vincent and the Grenadines in April. School safety is another major element of the CDM Strategy. An initiative launched in 2017, the forum is designed to also help implement UNDRR's Worldwide Initiative for Safe Schools, the Samoa Action Plan for Small Island Developing States, the Global Action Program on Education for Sustainable Development, Sendai and the Sustainable Development Goals. Specific outcomes included the updating of the Caribbean Regional Roadmap on School Safety and adherence by Curacao, Grenada, Jamaica, Sint Maarten and Suriname to the Antigua and Barbuda Declaration on School Safety, joining 12 other parties. ${ }^{29} \mathrm{CDEMA}$ also signed a memorandum of understanding with

26 'Report of the Multi-Hazard Early Warning Systems in the Caribbean: Achievements and Strategic Path Forward High-Level Handover Meeting' (21 February 2019), <https://www .cdema.org/component/jdownloads/send/25-mhews/169-report-of-the-multi-hazard -early-warning-systems-in-the-caribbean-achievements-and-strategic-path-forward -high-level-handover-meeting $>3$.

27 CREWS, 'Historical signing of commitment statements by Caribbean countries to strengthen early warning systems' (26 February 2019) <https://www.crews-initiative .org/en/news/historical-signing-of-commitment-statements-caribbean-countries -strengthen-early-warning>.

28 CDEma, 'Joint Meetings for the Regional Validation of the National Model Multi-Hazard Early Warning Systems (MHEWS) Policy 12th-14th, November, 2019 In Saint Lucia' CDEMA News <https://www.cdema.org/news-centre/events/1993-joint-meetings-for -the-regional-validation-of-the-national-model-multi-hazard-early-warning-systems -mhews-policy-12th-14th-november-2019-in-saint-lucia\#documents-4>; 'Fourth Meeting of the Regional Early Warning System Consortium: Concept Note and Agenda' (14 November 2019) <https://www.cdema.org/Concept_Note_and_Agenda_for_4th _REWSC_Meeting_(REWSC_19-11-14_DOC_1.0).pdf>.

29 'Second Caribbean Ministerial Forum on School Safety CDEMA' PreventionWeb (29-30 April 2019) <https://www.preventionweb.net/events/view/63939?id=63939>; '5 Countries in the Caribbean Region Adopt the Antigua And Barbuda Declaration on 
the Caribbean Regional Fisheries Mechanism to incorporate CDM principles and climate change resilience in the fisheries and aquaculture sector within CARICOM. ${ }^{30}$

On the regional assistance front, Synergy, CDEMA's operational preparedness and response exercise, took place in Barbados in July. The event is designed to test the operation of the agency's long-standing Regional Response Mechanism (RRM), a multi-tiered humanitarian response surge arrangement, along with RRM protocols and the related Regional Coordination Plan (RCP). ${ }^{31}$ The RRM was activated at the request of the Bahamas during Hurricane Dorian in late August. ${ }^{32}$

Beyond the specific efforts of CDEMA, Caribbean governments in 2019 were highly active in a variety of other settings, resulting in an impressively growing corpus of regional soft law in the field. One noteworthy development includes the launch of a new Caribbean Action Plan on Health and Climate Change in conjunction with the Pan American Health Organization in May. The plan emerged from the World Health Organization and the United Nations Framework Convention on Climate Change's Special Initiative on Climate Change and Health in Small Island Developing States. Participating governments agreed to enhance climate change and health focused education and research, to promote the construction of climate-resilient health facilities, improve health surveillance, and develop preparedness plans in the sector. ${ }^{33}$ Also within the climate change sphere, 18 Caribbean countries and territories and 12 international and regional organizations participated in the Caribbean

School Safety' CDEMA News (1 May 2019) <https://www.cdema.org/news-centre/press -releases/1904-5-countries-in-the-caribbean-region-adopt-the-antigua-and-barbuda -declaration-on-school-safety>.

30 CARICOM, 'CRFM, CDEMA sign agreement to enhance disaster management, resilience in fisheries', <https://today.caricom.org/2019/o7/31/crfm-cdema-sign-agree ment-to-enhance-disaster-management-resilience-in-fisheries/>.

31 CDEMA, 'CDEMA Kicks Off Synergy Exercise Focused on Strengthening Regional Coordination in Disaster Management' CDEMA News (12 July 2019) <https://www.cdema .org/news-centre/press-releases/1929-cdema-kicks-off-synergy-exercise-focused-on -strengthening-regional-coordination-in-disaster-management>.

32 CDEmA, 'CDEMA Deploys Teams to Support the Bahamas Ahead of the Impact of Hurricane Dorian' (31 August 2019) <https://www.cdema.org/news-centre/press-releases/ 1955-cdema-deploys-teams-to-support-the-bahamas-ahead-of-the-impact-of-hurri cane-dorian>.

33 PAHo, 'New Action Plan on Health and Climate Change calls for health to be front and center of climate change planning in the Caribbean' (3 May 2019) <https://www.paho .org/hq/index.php?option=com_content\&view=article\&id=15125:new-action-plan-on -health-and-climate-change-calls-for-health-to-be-front-and-center-of-climate-change -planning-in-the-caribbean\&Itemid $=1926 \&$ lang=en $>$. 
Migration Consultations (CMC) in partnership with the International Organization of Migration in June. An informal process launched in 2016, the Consultations seek to facilitate joint strategies addressing disaster displacement, a critical matter in the region given its 'poor infrastructure, land use, and low adaptive capacity, coupled with geographically exposed populations. ${ }^{34} \mathrm{~A}$ December technical meeting took steps toward formalizing the CMC process, drafting a declaration on the subject and framing a regional action plan, with an eye toward securing a high-level endorsement for these elements in 2020. ${ }^{35}$

National level disaster law development also took place. Saint Lucia engaged in several national stakeholder consultations related to its CDM-oriented legislative review process, along with updating its MHEws regulations to provide greater inclusion of the disabled and other vulnerable populations. ${ }^{36} \mathrm{In}$ Jamaica, its 2018 Building Act went into effect. The Act is 'a comprehensive legislative response to the challenges of applying contemporary international standards to the built environment and to those who construct it, monitoring and enforcing these standards, and cauterizing unauthorized land use including squatting. In this regard, the Act facilitates the realization of the third and fourth Global Objectives of the Sendai Framework.' ${ }^{37}$ Finally, CDEMA signed a Memorandum of Understanding with the Netherlands, to further integrate the Dutch Caribbean islands of Aruba, Curaçao, Sint Maarten and the public entities of Bonaire, Sint Eustatius and Saba into CDEMA's activities. The MOU

34 Caribbean Migration Consultations, 'Regional Consultation Towards a Framework for Regional Cooperation on Human Mobility in the Context of Disasters and the Adverse Effects of the Environmental Changes in the Caribbean' <https://caribbeanmigration .org/events/regional-consultation-towards-framework-regional-cooperation-human -mobility-context-disasters $>$.

CMC, 'Preparatory Meeting for a Regional Approach to Migration and International Protection: Concept Note' <https://caribbeanmigration.org/sites/default/files/concept _note_and_agenda-f.pdf>.

36 cDema, 'Strengthening the Legal Framework For Early Warning Systems in Saint Lucia' CDEMA News (29 July 2019) <https://www.cdema.org/news-centre/ press-releases/1937-strengthening-the-legal-framework-for-early-warning-systems -in-saint-lucia>; 'Ninth Meeting of the Council of Ministers of the Caribbean Disaster Emergency Management Agency (CDEMA), June 28, 2019, Turks and Caicos Islands, Report of Results of the CDEMA Corporate Plan 2017-2020 and Work-Plan - Year 2: September 1, 2018 - February 28, 2019' 25, <https://www.cdema.org/component/jdown loads/send/35-council-meeting/178-report-of-the-results-of-the-cdema-cu-annual-work -plan-for-the-corporate-plan-2017-2020-year-2-cnc19-o9-4-1>.

37 'Jamaica Country Statement: 2018 Global Platform for Disaster Risk Reduction, Cartagena, Colombia' <https://eird.org/pri8/declaraciones/jamaica-statement.pdf>. 
will also progress Sint Maarten toward CDEMA membership and enhance the Dutch navy's role in regional disaster response operations. ${ }^{38}$

While this entry has focused on respective developments within North America, Central America and the Caribbean, a special mention should be made too of the cross-hemispheric efforts of the ParlAmericas Open Parliament Network. ParlAmericas is an institutional framework consisting of 35 countries from the region dedicated to fostering democratic processes among its member legislatures and common action on matters of shared concern. In 2019 it passed a Parliamentary Protocol for Disaster Risk Reduction and Climate Change Adaptation. The Protocol encourages national parliaments to incorporate DRR perspectives when devising legislation, engaging in political oversight and during the passage of national budgets. It also socializes legislative branches around the content and purposes of the Sendai Framework. ${ }^{39}$

Hailing the importance of the Protocol, Raúl Salazar, the head of the Regional Office of UNDRR Americas, captured the significance of the instrument in a way that encapsulates disaster law developments throughout the region in 2019. He noted: '(...) important progress has been seen in a great number of countries that have developed regulatory frameworks with a comprehensive approach to managing disaster risk, as the Sendai Framework recommends. It is important for countries in our region to continue with efforts to integrate disaster risk reduction in their national and local regulatory and legislative frameworks, as these help the public and private sectors to advance risk governance, strengthening their institutions and mechanisms to adequately guide, coordinate, and provide oversight for disaster risk reduction and public policies (...).40

38 CDEMA, 'CDEMA Signs Memorandum of Understanding With the Government of the Kingdom of the Netherlands' CDEMA News (8 July 2019) <https://www.cdema.org/ news-centre/press-releases/1925-cdema-signs-memorandum-of-understanding-with -the-government-of-the-kingdom-of-the-netherlands $>$.

39 ParlAmericas and UNISDR, 'Parliamentary Protocol for Disaster Risk Reduction and Climate Change Adaptation Aligned With the Sendai Framework for Disaster Risk Reduction 2015-2030' (February 2019) <http://parlamericas.org/uploads/documents/ ENG_Protocolo_DRR_Online_Version.pdf $>$.

40 ParlAmericas and UNDRR, Joint Press Release, "The Parliamentary Protocol for Disaster Risk Reduction and Climate Change Adaptation was officially presented' (9 May 2019) $<$ http://www.parlamericas.org/uploads/documents/PR_DRR_Protocol_Climate_Change _ENG.pdf $>$. 